\section{Contraceptive Counseling and Use among Women with Poorer Health}

\author{
Jessica K. Lee ${ }^{1 *}$, Sara M. Parisi ${ }^{2}$ and Eleanor Bimla \\ Schwarz ${ }^{1,2,3,4}$
}

\begin{abstract}
Background: To explore associations between health status, contraceptive counseling and contraceptive use.

Methods: Women aged 18-50 visiting one of 4 primary care clinics were invited to complete surveys after their visit. Perceived health status was measured using a 5-point scale. Among those considered at risk of unintended pregnancy, logistic regression was used to investigate associations between health status and contraceptive counseling and use.

Findings: Women reporting poorer health had decreased odds of receiving some contraceptive counseling at their visit $(\mathrm{aOR}=0.62$, $\mathrm{Cl}=0.39,0.97)$ and using some contraception at last intercourse (aOR=0.63, $\mathrm{Cl}=0.41,0.97$ ) compared to women reporting better health. However, among women with poorer health, receipt of counseling about hormonal contraception was associated with increased odds of using hormonal methods $(\mathrm{aOR}=8.22, \mathrm{Cl}=1.77$, 38.19 ). Only $7 \%$ of women in poorer health received counseling on highly effective reversible contraception.
\end{abstract}

Conclusions: Women in poorer health may be at risk of adverse reproductive health outcomes and should receive counseling on safe hormonal and highly effective reversible contraceptives.

\section{Keywords}

Contraceptive counseling; Women's health; Primary care

\section{Introduction}

Over 73 million women in the United States are of reproductive age, accounting for more than $48 \%$ of the female population [1]. Of these women, over $25 \%$ suffer from chronic conditions including hypertension, diabetes, depression, and vascular disease [2-4] which do not affect fertility but may increase the risk of pregnancy complications and adverse birth outcomes [5-10]. Use of effective contraception by women with chronic conditions can enable them to plan their pregnancies and optimize maternal and fetal outcomes. The effectiveness of contraceptive counseling [11] and contraception as part of preventative health efforts are recognized by their coverage without co-pay in the Affordable Care Act.

As Primary Care Providers (PCPs) are the principal source of

*Corresponding author: Jessica K. Lee, Department of Obstetrics and Gynecology, Magee Women's Hospital, University of Pittsburgh Medical Center, 230 McKee Place Suite 600 Pittsburgh, PA 15213, USA, Tel: 412-586-9836; Fax: 412-692-4838; E-mail: Leejk2@upmc.edu

Received: December 20, 2012 Accepted: February 05, 2013 Published: February 11, 2013 health care for many women with chronic conditions [12] and PCPs prescribe the majority of potentially teratogenic medications $[13,14]$, they are well positioned to provide contraceptive counseling to these high-risk patients [11]. Unfortunately, though many women with chronic conditions expect to talk about birth control with their physician [15], prior studies have found that women with poor health may receive less contraceptive counseling than healthy women or inaccurate messages about which contraceptive methods are safe given their health condition [16,17]. The U.S. Medical Eligibility Criteria for Contraceptive Use was created as a resource to better guide physician recommendations for safe contraception in women with chronic conditions. It has been previously reported that women who received contraceptive counseling from their PCP were more likely to use contraception [11]. Similarly, another recent study found that birth control use was related to provider recommendations [18]. As women with chronic conditions are more likely to have unintended pregnancies [19], we explored whether women's health status is related to receipt of contraceptive counseling from a PCP and use of contraception. We also explored whether contraceptive counseling is associated with increased likelihood of contraceptive use for both women with poorer health and women with better health.

\section{Materials and Methods}

\section{Data collection}

All women aged 18-50 who visited one of four primary care clinics in western Pennsylvania between October 2008 and April 2010 were invited by trained research staff to complete an online survey 7 to 30 days after their visit. These clinics included three community-based family practice clinics, and one academic general internal medicine clinic, all of which provide care to both publicly and privately insured patients. Interested participants provided signed informed consent and received instructions regarding accessing the online survey. Women who preferred to complete the survey by phone were able to do so. Upon completing the survey, participants received a $\$ 10$ gift card to compensate them for time. This study was approved by the University of Pittsburgh Institutional Review Board and ethics committee.

\section{Survey instrument}

The survey collected information on patients' age, education, race, marital status, household income, insurance status, medical assistance status, pregnancy intentions, and number of prior pregnancies, live births, abortions, and miscarriages. Health status was assessed using a single question with 5 response categories presented in a single line ("Poor", "Fair", "Good", "Very Good", "Excellent"), which we collapsed into a dichotomous variable by grouping those who reported "Poor" or "Fair" health (poorer health) and those who reported "Good", "Very good" or "Excellent" health (better health) [20]. Although we assessed women's health status with a widely used measure, this self-assessed measure is subjective [21]. We did not have information on the women's actual diagnoses, and women with serious, but well-controlled, conditions may have not reported poorer health. However, there are many studies validating the use of self-reported or self-rated health as a predictor of 
mortality and identifying vulnerable persons with the greatest health needs $[20,22,23]$. Pregnancy intention was measured using a single question with 5 response categories that allowed women to express ambivalence towards pregnancy [24]. Women were asked whether they received contraceptive counseling at their "survey visit" and what types of contraception they discussed at this visit. They were also asked which methods of contraception they used when they last had intercourse, and which they had used in the past 3 months. When considering contraceptive use at last intercourse, we examined (1) use of any reversible contraceptive method (condom, diaphragm, pills, patch, ring, injection, implant, or intrauterine device (IUD), (2) use of certain hormonal methods (pills, patch, ring, or injection) and (3) use of highly effective reversible methods (IUD or implant).

\section{Statistical analysis}

We excluded women who were not at risk of unintended pregnancy (i.e. were currently pregnant or trying to get pregnant, had undergone surgical sterilization, had a partner with vasectomy, had never had sex with a man or answered not applicable when asked about contraceptive counseling). Finally, we excluded women who did not complete the questions about contraceptive counseling or contraceptive use at last intercourse.

We used chi-square tests to compare differences in the sociodemographic and reproductive characteristics of women reporting better vs. poorer health. We then compared receipt of counseling and use of contraception at last intercourse by health status using chisquare tests and logistic regression models adjusted for age category, race, education level, and income. As a sensitivity analysis, we re-ran the same statistics grouping the women reporting "fair" health with the women who reported better health and considering only those reporting "poor" health as poorer health, without dramatic change in any of our significant results. Finally, we explored the relationship between contraceptive use at last intercourse and two types of predictor variables: 1) receipt of any contraceptive counseling and 2) receipt of contraceptive counseling regarding certain hormonal methods and 3) receipt of contraceptive counseling about highly effective reversible methods. For each set of outcomes and predictors, we controlled for age category, education level, race, and income. Our sample size became much more limited when trying control for all possible confounders, thus we choose what we thought to be the most important variables to control for from Table 1 . We specifically could not stratify by visit type as this was drawn from EMR with a wide variety of possible visit types and not available for all patients. Analyses were conducted using Stata 10.0 (StataCorp. College Station, TX).

\section{Results}

Nineteen percent of eligible women who visited the primary care clinics completed surveys $(n=1,965)$. Seventy-five percent of respondents were visiting a doctor (49 doctors saw patients involved in the survey) they considered their PCP on the survey visit. On average, women completed surveys 9.5( \pm 6.2 ) days (median (IQR): 7(5)) after visiting a study clinic (range $=5-30$ days). Forty-seven percent of the visits to the clinic were categorized as "return sick" visits, $20 \%$ as "return patient" visits, and $9 \%$ as "comprehensive" visits $(\mathrm{n}=1,052)$. Of the 1,965 who completed the survey, we excluded 757 who were not in need of reversible contraception (33 who thought they were pregnant, 39 who were trying to get pregnant (pregnancy intention category), 288 women who reported surgical sterilization
Table 1: Sample characteristics at most recent visit to a primary care clinic by perceived health status.

\begin{tabular}{|c|c|c|c|}
\hline Characteristics & $\begin{array}{c}\text { Better } \\
\text { Health } \\
\mathrm{N}=1,041 \\
\%\end{array}$ & $\begin{array}{c}\text { Poorer } \\
\text { Health } \\
\mathrm{N}=128 \\
\%\end{array}$ & p-value \\
\hline Age $(N=1,156)$ & & & 0.006 \\
\hline $18-21$ & 12.3 & 6.4 & \\
\hline $22-30$ & 37.3 & 27.0 & \\
\hline $31-40$ & 30.5 & 38.9 & \\
\hline $41-50$ & 19.9 & 27.8 & \\
\hline Education $(\mathrm{N}=1,165)$ & & & 0.001 \\
\hline High school diploma or less & 12.0 & 22.7 & \\
\hline Some college or more & 88.0 & 77.3 & \\
\hline Marital Status $(\mathrm{N}=1,155)$ & & & 0.04 \\
\hline Married or living with partner & 56.2 & 46.5 & \\
\hline Other & 43.8 & 53.5 & \\
\hline Race $(N=1,166)$ & & & $<0.001$ \\
\hline White & 94.1 & 82.8 & \\
\hline Black & 2.2 & 10.2 & \\
\hline Other & 3.7 & 7.0 & \\
\hline Household Income $(\mathrm{N}=1,051)$ & & & $<0.001$ \\
\hline Less than $\$ 20,000 / y r$ & 6.1 & 18.3 & \\
\hline Less than $\$ 21,000-50,000 / y r$ & 34.5 & 53.0 & \\
\hline More than $\$ 50,000 / y r$ & 59.4 & 28.7 & \\
\hline Health insurance $(\mathrm{N}=1,154)$ & & & 0.09 \\
\hline No & 3.3 & 6.4 & \\
\hline Yes & 96.7 & 93.7 & \\
\hline Medical Assistance $(\mathrm{N}=1,164)$ & & & $<0.001$ \\
\hline No & 88.5 & 58.7 & \\
\hline Yes & 8.2 & 35.7 & \\
\hline Don't Know & 3.3 & 5.6 & \\
\hline Prior pregnancy $(\mathrm{N}=1,160)$ & & & 0.04 \\
\hline No & 54.2 & 44.4 & \\
\hline Yes & 45.8 & 55.6 & \\
\hline Prior Live Births ${ }^{a}(N=533)$ & & & 0.10 \\
\hline 0 & 7.7 & 14.7 & \\
\hline 1 & 33.6 & 25.0 & \\
\hline $2+$ & 58.7 & 60.3 & \\
\hline Prior Abortion $(\mathrm{N}=527)$ & & & 0.005 \\
\hline 0 & 84.5 & 70.6 & \\
\hline $1+$ & 15.5 & 29.4 & \\
\hline Prior Miscarriage ${ }^{a}(N=530)$ & & & 0.10 \\
\hline 0 & 71.4 & 61.8 & \\
\hline $1+$ & 28.6 & 38.2 & \\
\hline $\begin{array}{l}\text { Current Pregnancy Intentions } \\
(\mathrm{N}=1,134)\end{array}$ & & & 0.004 \\
\hline Wouldn't mind pregnancy & 12.5 & 14.5 & \\
\hline Don't Know & 6.4 & 15.4 & \\
\hline Wouldn't mind avoiding pregnancy & 4.5 & 4.3 & \\
\hline Trying to avoid pregnancy & 76.6 & 65.8 & \\
\hline
\end{tabular}

${ }^{a}$ Asked only of those women reporting a prior pregnancy.

or reported having a partner with a vasectomy, 92 who had never had sex with a man, and 305 women who responded "not applicable" when asked if they had received contraceptive counseling). We also eliminated an additional 39 women who had missing information for either contraceptive use at last intercourse or receipt of contraceptive counseling at last visit leaving 1,169 women for analysis. For models investigating the relationship between contraceptive counseling and 
use, we further excluded 192 women who had not had sex with a man in the past 3 months, leaving 977 for this part of the analysis.

When asked about their health status, $13.6 \%$ of respondents reported "Excellent" health, 43.5\% reported "Very good" health, $32.0 \%$ reported "Good" health, 9.3\% reported "Fair" health and 1.6\% reported "Poor" health. Subsequently, 10.9\% ( $\mathrm{n}=128)$ of women were categorized as reporting poorer health.

Women reporting poorer health were more frequently older than 30 years of age and received medical assistance. The women were also less frequently reported completing at least some college, to be married or living with a partner, to be white, and to have a household income of more than $\$ 50,000 /$ year (Table 1 ). Women reporting poorer health more frequently reported having had a prior pregnancy, had an abortion and less frequently reported that they were trying to avoid pregnancy (Table 1). The majority of women in poorer health reported having had sex within the past 3 months, although they less frequently reported having done so than women in better health $(64.1 \%$ poorer health vs. $86.0 \%$ better health, $\mathrm{p}<0.001)$.

In bivariate analysis, women in poorer health less frequently reported receiving any contraceptive counseling at their clinic visit than women in better health $(\mathrm{p}=0.03)$ (Table 2). More specifically, women in poorer health less frequently received counseling on hormonal methods $(\mathrm{p}=0.003)$. Women in poorer health also less frequently reported use of some contraception at last intercourse $(\mathrm{p}<0.001)$. More specifically, women in poorer health less frequently used hormonal contraception $(\mathrm{p}<0.0001)$. There were no significant differences in the percent of women using highly effective reversible contraception by health status $(5.6 \%$ among women in better health and $7.8 \%$ among women in poorer health).

In adjusted models, women in poorer health remained less likely to have received contraceptive counseling than women in better health. Women in poorer health also remained less likely to have used any contraception at last intercourse. Additionally, women with poorer health remained less likely to be counseled on hormonal contraception or to have used hormonal contraception. Women in poorer health also remained as likely to be counseled on highly effective reversible contraception or to have used these methods at last intercourse as women in better health (Table 2).

In models investigating the relationship between receipt of counseling and use of contraception at last intercourse (Table 3), those women in poorer health who had been counseled on hormonal methods were more likely to have used hormonal methods at last intercourse. The relationship between counseling about specific contraception and use of those methods was similar for women in better health, though notably, women in better health were more likely to use highly effective reversible contraception if specifically counseled on these methods (Table 3 ).

\section{Conclusion}

This study of women served by 4 primary care practices in western Pennsylvania found that women with poorer health were less likely to receive contraceptive counseling and less likely to use contraception than those with better health, putting them at increased risk for unintended pregnancy. Prior studies have found that women in poor health are at increased risk for unintended pregnancy and have unintended pregnancies at rates that match or exceed the rates in the general population [14,25-27]. Additionally, we found that the majority of women in poorer health more frequently reported having intercourse in the past 3 months, emphasizing the fact that many women in poor health remain at risk for unintended pregnancy. In accordance with results from a previous study [11], we found that targeted counseling on hormonal contraception was associated

Table 2: Contraceptive Status and Family Planning Services Received at Most Recent Visit to a Primary Care Clinic by Health Status.

\begin{tabular}{|c|c|c|c|c|}
\hline Family Planning Services & $\begin{array}{c}\text { Better Health } \\
\begin{array}{c}\mathrm{N}=1,041 \\
\%\end{array}\end{array}$ & $\begin{array}{c}\text { Poorer Health } \\
\mathrm{N}=128 \\
\%\end{array}$ & p-value & $\begin{array}{c}\mathrm{aOR}^{\mathrm{a}} \\
\text { (95\% Confidence Interval) }\end{array}$ \\
\hline Received some contraceptive counseling & 39.9 & 29.7 & 0.03 & *0.62 (0.39-0.97) \\
\hline Received counseling on highly effective methods & 7.1 & 7.0 & 0.97 & $0.77(0.34-1.78)$ \\
\hline Received counseling on hormonal methods & 29.5 & 17.2 & 0.003 & ${ }^{*} 0.50(0.29-0.86)$ \\
\hline Used some contraception at last intercourse & 68.3 & 51.6 & $<0.001$ & *0.63 (0.41-0.97) \\
\hline Used highly effective reversible methods & 5.6 & 7.8 & 0.31 & $1.58(0.73-3.41)$ \\
\hline Used hormonal methods & 42.6 & 25.0 & $<0.001$ & $0.52(0.32-0.84)$ \\
\hline Used barrier methods & 34.8 & 30.5 & 0.32 & $0.95(0.61-1.49)$ \\
\hline
\end{tabular}

a Adjusted odds ratio associating women of poorer health with women of better health (adjusted for age category, education level, race, and household income). *Significant Odds Ratios

Table 3: Association of Content of Contraceptive Counseling with Contraceptive Use at Last Intercourse among Women in Poorer Health ${ }^{\text {. }}$.

\begin{tabular}{|c|c|c|c|c|c|c|}
\hline \multirow{3}{*}{ Content of Counseling } & \multicolumn{2}{|c|}{$\begin{array}{l}\text { Use of Any Reversible } \\
\text { Contraception }\end{array}$} & \multicolumn{2}{|c|}{ Use of Hormonal Methods } & \multicolumn{2}{|c|}{$\begin{array}{l}\text { Use of Highly Effective Reversible } \\
\text { Methods }\end{array}$} \\
\hline & Poorer Health & Better Health & Poorer Health & Better Health & Poorer Health & Better Health \\
\hline & $\mathrm{N}=72$ & $\mathrm{~N}=790$ & $\mathrm{~N}=72$ & $N=790$ & $\mathrm{~N}=72$ & $N=790$ \\
\hline Discussed any reversible contraceptives & $\begin{array}{c}0.68 \\
(0.22-2.07)\end{array}$ & $\begin{array}{c}2.71 \\
(1.89-3.89)\end{array}$ & $\begin{array}{c}1.57 \\
(0.47-5.28)\end{array}$ & $\begin{array}{c}2.07 \\
(1.51-2.84)\end{array}$ & $\begin{array}{c}0.20 \\
(0.02-2.43)\end{array}$ & $\begin{array}{c}2.05 \\
(1.11-3.80)\end{array}$ \\
\hline Counseling about hormonal methods & $\begin{array}{c}1.31 \\
(0.30-5.76)\end{array}$ & $\begin{array}{c}2.34 \\
(1.56-3.53)\end{array}$ & $\begin{array}{c}8.22 \\
(1.77-38.19)\end{array}$ & $\begin{array}{c}3.79 \\
(2.66-5.40)\end{array}$ & b & $\begin{array}{c}0.14 \\
(0.04-0.47)\end{array}$ \\
\hline $\begin{array}{l}\text { Counseling about highly effective reversible } \\
\text { methods }\end{array}$ & $\begin{array}{c}0.70 \\
(0.11-4.60)\end{array}$ & $\begin{array}{c}2.88 \\
(1.40-5.90)\end{array}$ & $\begin{array}{c}0.68 \\
(0.06-7.19)\end{array}$ & $\begin{array}{c}0.60 \\
(0.34-1.08)\end{array}$ & $\begin{array}{c}3.30 \\
(0.25-43.40)\end{array}$ & $\begin{array}{c}15.05 \\
(7.67-29.61)\end{array}$ \\
\hline
\end{tabular}

adjusted for age category, education level, race, and household income.

${ }^{\mathrm{b}}$ All those who use highly effective reversible methods were counseled on hormonal methods. 
with increased use of these methods by women with poorer health. However, women in poorer health who received general contraceptive counseling were not more likely to have used any contraception at last intercourse, suggesting that counseling may be more effective for this vulnerable population when it focuses specifically on the safety and effectiveness of hormonal or more effective methods of contraception within the context of the woman's health status.

Although most women with poorer health are ideal candidates for use of highly effective reversible contraception, only a small proportion of the respondents with poorer health reported use of these methods; women with poorer health were not more likely to receive counseling on these methods than women in better health. Notably, the relationship between counseling and use of these highly effective methods was stronger for women in better health than women in poorer health. While this could have been due to sample size differences, it may also point to problems among women in poorer health with regards to the cost of and access to highly effective reversible contraception. A prior study noted that women with diabetes were less likely to receive contraceptive counseling or prescriptions and more likely to undergo tubal ligation rather than use highly effective reversible contraception [28]. Women in poorer health may be financially challenged with the costs of other medications, making highly effective reversible contraceptive options less discussed or inquired about. Women in poorer health were less likely to use and receive counseling on hormonal methods. This may be due to the fact that some PCPs are unaware of which methods are appropriate and safe for women with chronic conditions that increase risk of thromboembolism. Educating PCPs on use of these methods by women with poorer health could increase the provision of more specific counseling and increase use of these methods by women with chronic conditions for which hormonal contraception would be safe $[27,29]$.

Strengths of this study include the involvement of clinics that serve both privately and publicly insured women in both academic and community-based primary care settings. However, there are limitations that must be considered. There is the possibility for recall bias; women in poorer health would be expected to have had more complicated and lengthy visits with their PCPs and because of this may have been less likely to be counseled or to recall details of any contraceptive counseling received, and women who chose to use a method could have been more likely to recall having been counseled about it. We did not ask about prior or recent contraceptive counseling, but rather counseling received during a particular visit. A large proportion of the visits were "return sick" visits which may have been more targeted towards a patient's chief complaint rather than on preventative health measures like contraception. There was also no way to ensure that patients' last intercourse occurred after they visited their PCP, as this was not specifically asked by the survey. However, as surveys were completed up to thirty days after women visited their primary care clinic, and the majority of women aged 18-50 have sex at least monthly $[30,31]$, we believe that in most cases women's last episode of intercourse followed receipt of counseling. The response rate the survey is also a limitation, however web-based surveys may often have a much lower response rate than paper-based surveys, a prior clinic study showed $17.9 \%$ versus $73.2 \%$ [32] which may be due to the population's education level and access to computers. Finally, the relatively small number of women reporting poorer health status limited our power to detect other significant differences which may in fact exist. Larger studies are needed, as are studies that assess the effectiveness of different approaches to contraceptive counseling among women with poorer health.

\section{Implications for practice and/or policy}

We found that primary care patients with poorer health were less likely to receive contraceptive counseling and less likely to have used contraception at last intercourse. However, women in poorer health who did receive targeted contraceptive counseling on hormonal methods were more likely to report use of these methods at last intercourse. Targeted contraceptive counseling regarding safe hormonal options and highly effective reversible methods should thus be encouraged for all women, and in particular for women who face increased risks of adverse pregnancy outcomes. These considerations are especially important in the setting of the Affordable Care Act where contraception and contraceptive counseling are emphasized as effective preventative health services to be offered without copayment.

\section{Acknowledgements}

The data used in this analysis was collected with funding from AHRQ R18HS017093. Dr. Schwarz was funded by NICHD K23 HD051585.

\section{References}

1. Bureau, USC (2009) Population by Age and Sex: 2009. Census US Profile.

2. Behavioral Risk Factor Surveillance System (2006) Annual report. Department of Health.

3. NHANES (2003-2006) National Health and Nutrition Examination Survey.

4. Verbrugge LM, Patrick DL (1995) Seven chronic conditions: their impact on US adults' activity levels and use of medical services. Am J Public Health 85: 173-182.

5. Zetterström K, Lindeberg SN, Haglund B, Hanson U (2005) Maternal complications in women with chronic hypertension: a population-based cohort study. Acta Obstet Gynecol Scand 84: 419-424.

6. Mahadevan U, Sandborn WJ, Li DK, Hakimian S, Kanel S, et al. (2007) Pregnancy outcomes in women with inflammatory bowel disease: a large community-based study from Northern California. Gastroenterology 133: 1106-1112.

7. Kornfeld D, Cnattingius S, Ekbom A (1997) Pregnancy outcomes in women with inflammatory bowel disease--a population-based cohort study. Am J Obstet Gynecol 177: 942-946.

8. Rosenberg TJ, Garbers S, Lipkind H, Chiasson MA (2005) Maternal obesity and diabetes as risk factors for adverse pregnancy outcomes: differences among 4 racial/ethnic groups. Am J Public Health 95: 1545-1551.

9. Reddy UM, Laughon SK, Sun L, Troendle J, Willinger M, et al. (2010) Prepregnancy risk factors for antepartum stillbirth in the United States. Obstet Gynecol 116: 1119-1126.

10. Jones DC, Hayslett JP (1996) Outcome of pregnancy in women with moderate or severe renal insufficiency. N Engl J Med 335: 226-232.

11. Lee JK, Parisi SM, Akers AY, Borrero S, Schwarz EB (2011) The Impact of Contraceptive Counseling in Primary Care on Contraceptive Use. J Gen Intern Med 26: 731-736.

12. Henderson JT, Weisman CS, Grason H (2002) Are two doctors better than one? Women's physician use and appropriate care. Women's Health Issues 12: $138-149$.

13. Schwarz EB, Maselli J, Norton M, Gonzales R (2005) Prescription of teratogenic medications in United States ambulatory practices. Am J Med 118: $1240-1249$.

14. Schwarz EB, Postlethwaite DA, Hung YY, Armstrong MA (2007) Documentation of contraception and pregnancy when prescribing potentially teratogenic medications for reproductive-age women. Ann Intern Med 147: 370-376. 
15. Schwarz EB, Manzi S (2008) Risk of unintended pregnancy among women with systemic lupus erythematosus. Arthritis Rheum 59: 863-866.

16. Rogers P, Mansour D, Mattinson A, O'Sullivan JJ (2007) A collaborative clinic between contraception and sexual health services and an adult congenital heart disease clinic. J Fam Plann Reprod Health Care 33: 17-21.

17. Schwarz EB, Maselli J, Gonzales R (2006) Contraceptive counseling of diabetic women of reproductive age. Obstet Gynecol 107: 1070-1074.

18. Harelick L, Viola D, Tahara D (2011) Preconception health of low socioeconomic status women: assessing knowledge and behaviors. Women's Health Issues 21: 272-276.

19. Chor J, Rankin K, Harwood B, Handler A (2011) Unintended pregnancy and postpartum contraceptive use in women with and without chronic medical disease who experienced a live birth. Contraception 84: 57-63.

20. Benyamini Y (2011) Why does self-rated health predict mortality? An update on current knowledge and a research agenda for psychologists. Psychol Health 26: 1407-1413.

21. Banerjee D, Perry M, Tran D, Arafat R (2010) Self-reported health, functional status and chronic disease in community dwelling older adults: untangling the role of demographics. J Community Health 35: 135-141.

22. Nery Guimarães JM, Chor D, Werneck GL, Carvalho MS, Coeli CM, et al. (2012) Association between self-rated health and mortality: 10 years followup to the Pró-Saúde cohort study. BMC Public Health 12: 676.

23. DeSalvo KB, Bloser N, Reynolds K, He J, Muntner P (2006) Mortality prediction with a single general self-rated health question. J Gen Intern Med 21: $267-275$.
24. Kavanaugh ML, Schwarz EB (2009) Prospective assessment of pregnancy intentions using a single- versus a multi-item measure. Perspect Sex Reprod Health 41: 238-243.

25. St James PJ, Younger MD, Hamilton BD, Waisbren SE (1993) Unplanned pregnancies in young women with diabetes. An analysis of psychosocial factors. Diabetes Care 16: 1572-1578.

26. Davis AR, Pack AM, Kritzer J, Yoon A, Camus A (2008) Reproductive history, sexual behavior and use of contraception in women with epilepsy. Contraception 77: 405-409.

27. Dragoman M, Davis A, Banks E (2010) Contraceptive options for women with preexisting medical conditions. J Womens Health (Larchmt) 19: 575-580.

28. Schwarz EB, Postlethwaite D, Hung YY, Lantzman E, Armstrong MA, et al (2012) Provision of contraceptive services to women with diabetes mellitus. J Gen Intern Med 27: 196-201.

29. Teal SB, Ginosar DM (2007) Contraception for women with chronic medica conditions. Obstet Gynecol Clin North Am 34: 113-126.

30. Davison SL, Bell RJ, LaChina M, Holden SL, Davis SR (2008) Sexual function in well women: stratification by sexual satisfaction, hormone use, and menopause status. J Sex Med 5: 1214-1222.

31. Addis IB, Van Den Eeden SK, Wassel-Fyr CL, Vittinghoff E, Brown JS, et al (2006) Sexual activity and function in middle-aged and older women. Obstet Gynecol 107: 755-764.

32. Kongsved SM, Basnov M, Holm-Christensen K, Hjollund NH (2007) Response rate and completeness of questionnaires: a randomized study of Internet versus paper-and-pencil versions. J Med Internet Res 9: e25.

\section{Author Affiliations}

'Department of Obstetrics and Gynecology, Magee Women's Hospital, University of Pittsburgh Medical Center, Pittsburgh, Pennsylvania, USA ${ }^{2}$ Department of Medicine, University of Pittsburgh, Pittsburgh, Pennsylvania, USA

${ }^{3}$ Department of Epidemiology, University of Pittsburgh, Pittsburgh, Pennsylvania, USA

${ }^{4}$ Department of Obstetrics, Gynecology, and Reproductive Sciences, University of Pittsburgh, Pittsburgh, PA, USA

\section{Submit your next manuscript and get advantages of SciTechnol} submissions

* 50 Journals

* 21 Day rapid review process

* 1000 Editorial team

* 2 Million readers

* More than 5000 facebogk

* Publication immediately after acceptance

* Quality and quick editorial, review processing

Submit your next manuscript at • www.scitechnol.com/submission 